\title{
Hexarelin modulates lung mechanics, inflammation, and fibrosis in acute lung injury
}

\author{
${ }^{1}$ Department of Medicine and Surgery, University of Milano-Bicocca, Monza - Italy \\ ${ }^{2}$ ASST Vimercate, Vimercate - Italy \\ ${ }^{3}$ Department of Biology, Lakehead University, Thunder Bay, Ontario - Canada
}

Vanessa Zambelli ${ }^{1}$, Laura Rizzi ${ }^{1}$, Paolo Delvecchio ${ }^{1}$, Elena Bresciani ${ }^{1}$, Emanuele Rezoagli ${ }^{1}$, Laura Molteni ${ }^{1}$, Ramona Meanti ${ }^{1}$, Maria Serena Cuttin ${ }^{2}$, Giorgio Bovo ${ }^{2}$, Silvia $\mathrm{Coco}^{1}$, Robert J Omeljaniuk ${ }^{3}$, Vittorio Locatelli ${ }^{1}$, Giacomo Bellani ${ }^{1}$, Antonio Torsello ${ }^{1}$

Vanessa Zambelli and Laura Rizzi contributed equally to this research.

\begin{abstract}
Introduction: Acute respiratory distress syndrome (ARDS) is an acute form of diffuse lung injury characterized by (i) an intense inflammatory response, (ii) increased pulmonary vascular permeability, and (iii) the loss of respiratory pulmonary tissue. In this article we explore the therapeutic potential of hexarelin, a synthetic hexapeptide growth hormone secretagogue (GHS), in an experimental model of ARDS. Hexarelin has anti-inflammatory properties and demonstrates cardiovascular-protective activities including the inhibition of cardiomyocyte apoptosis and cardiac fibrosis, both of which may involve the angiotensin-converting enzyme (ACE) system.

Methods: In our experimental model, ARDS was induced by the instillation of $100 \mathrm{mM} \mathrm{HCl}$ into the right bronchus; these mice were treated with hexarelin $(320 \mu \mathrm{g} / \mathrm{kg}$, ip) before (Pre) or after (Post) $\mathrm{HCl}$ challenge, or with vehicle. Respiratory system compliance, blood gas analysis, and differential cell counts in a selective bronchoalveolar lavage (BAL) were determined 6 or 24 hours after $\mathrm{HCl}$ instillation. In an extended study, mice were observed for a subsequent 14 days in order to assess lung fibrosis.

Results: Hexarelin induced a significant improvement in lung compliance and a reduction of the number of total immune cells in BAL 24 hours after $\mathrm{HCl}$ instillation, accompanied with a lower recruitment of neutrophils compared with the vehicle group. At day 14, hexarelin-treated mice presented with less pulmonary collagen deposition compared with vehicle-treated controls.

Conclusions: Our data suggest that hexarelin can inhibit the early phase of the inflammatory response in a murine model of $\mathrm{HCl}$-induced ARDS, thereby blunting lung remodeling processes and fibrotic development.
\end{abstract}

Keywords: ARDS, GHS (growth hormone secretagogues), Hexarelin, Inflammation, Lung fibrosis

\section{Introduction}

Acute respiratory distress syndrome (ARDS) is often underrecognized and undertreated, thereby contributing to a high mortality rate (1-3). ARDS constitutes an acute lung injury associated with (i) an intense inflammatory response, (ii) increased pulmonary vascular permeability, and (iii) the loss of aerated lung tissue (4). Diffuse alveolar damage is the

Received: September 24, 2021

Accepted: October 20, 2021

Published online: November 27, 2021

Corresponding author:

Laura Rizzi

School of Medicine and Surgery

University of Milano-Bicocca

via Cadore 48

20900 Monza (MB) - Italy

laura.rizzi@unimib.it most common morphological symptom of the acute phase of ARDS, and is characterized by the influx of neutrophils and macrophages into alveoli, and alteration of the alveolar epithelium (5). These alterations often progress to fibrotic development accompanied by a further decrease in pulmonary compliance (6). There is no documented and approved pharmacologic treatment for ARDS. Hexarelin is a synthetic hexapeptide that has already shown positive effects in experimental models of human pathologies such as epilepsy and cachexia (7-11). In particular, hexarelin reduced cardiac fibrosis in experimental models of myocardial infarction (12). Furthermore, we previously demonstrated that the protective effects of hexarelin on the cardiovascular system could be mediated by its interaction with the angiotensin-converting enzyme (ACE) system (13). Modulation of ACE activity associated with the reduction of angiotensin II synthesis may also be involved with reduced fibrosis development in the lung (14). In this study we have applied our validated experimental model of unilateral acid aspiration lung injury (16) to test specific growth hormone secretagogues (GHS) as potential 
adjunctive therapeutic tools for ARDS. Among GHS, ghrelin has demonstrated anti-inflammatory properties including inhibition of cardiac fibrosis (15). Consequently, this study examined the potential utility of hexarelin in the treatment of ARDS in our murine model.

The aim of this research was to ascertain whether hexarelin could have a potential therapeutic use to antagonize the inflammatory response and the lung fibrosis induced by unilateral acid aspiration in mice. The results of the present research demonstrate that hexarelin treatment reduces the development of lung fibrosis and further suggests that specific synthetic GHS could be developed in order to modulate lung and cardiac fibrosis such as those associated with COVID-19 infections.

\section{Materials and methods}

\section{Animals}

Male C57/BL6J mice (23-25 g; Harlan Laboratories, Udine, Italy) were used in this experimental study. Animals were housed five per cage in a limited access animal facility, with the room temperature at $20 \pm 2{ }^{\circ} \mathrm{C}$ and the relative humidity set at $55 \pm 10 \%$. Artificial lighting provided a $12 \mathrm{~h}$ light/12 h dark ( 7 am to $7 \mathrm{pm}$ ) cycle. The general condition of the animals before the experiment was assessed daily. The care and husbandry of animals were in conformity with the institutional guidelines in compliance with Italian and European laws and policies. The animal study was reviewed and approved by the Italian Ministry of Health (591/2017-PR) and by the Animal Care Unit of the University of Milano-Bicocca, Monza, Italy. In full respect of the Reduction principle of the $3 \mathrm{Rs}$, the number of animals/groups selected was to obtain reliable results and enough biological samples to perform the analysis planned.

\section{Chemicals}

Hexarelin (His/D-2-Methyl-Trp/Ala/Trp/D-Phe/Lys- $\mathrm{NH}_{2}$ ) (Sigma-Aldrich) was given at a dose of $320 \mu \mathrm{g} / \mathrm{kg}$ body weight, according to the assigned treatment group (see below).

\section{Experimental protocol}

Mice were anesthetized with ketamine ( $80 \mathrm{mg} / \mathrm{kg}$, ip) (Ketavet 100; Intervet Productions) and xylazine (4 mg/kg, ip) (Rompun 2\%; Bayer) and orotracheally intubated. Then, lung injury was induced in the right lung as described in Amigoni et al (16). The experimental protocol was divided into two time points including (i) the Acute ARDS study, in which animals were sacrificed after 6 or 24 hours following $\mathrm{HCl}$ instillation, and (ii) the Late ARDS study, with sacrifice performed 14 days after $\mathrm{HCl}$ instillation.

In the Acute ARDS study, mice were assorted into three treatment groups:

- Vehicle: mice received sterile physiological saline treatment (100 $\mu \mathrm{L}$, ip), immediately after $\mathrm{HCl}$ challenge;

- Post-Hex: mice received hexarelin $(320 \mu \mathrm{g} / \mathrm{kg}$, ip, $100 \mu \mathrm{L})$, immediately after $\mathrm{HCl}$ challenge;
- Pre-Hex: mice received hexarelin $(320 \mu \mathrm{g} / \mathrm{kg}$ ip, $100 \mu \mathrm{L})$ 2 and 1 day before and immediately after $\mathrm{HCl}$ challenge.

In the Late ARDS study, mice were assorted into two treatment groups:

- Vehicle: mice received sterile physiological saline $(100 \mu \mathrm{L}$, ip), immediately after $\mathrm{HCl}$ challenge and twice daily in the following 4 days;

- Hexarelin: mice received hexarelin treatment immediately after $\mathrm{HCl}$ challenge (entire dose, $320 \mu \mathrm{g} / \mathrm{kg}$ ip, $100 \mu \mathrm{L}$ ) and twice daily in the following 4 days (two half doses, $160 \mu \mathrm{g} / \mathrm{kg}$ ip, $100 \mu \mathrm{L})$.

A group of healthy mice ( $n=5$ ) did not undergo any of the surgical interventions and was sacrificed (Healthy Mice). When, at the moment of the sacrifice, we identified that $\mathrm{HCl}$ instillation involved the contralateral lung (the left one) through a macroscopic lung evaluation, the animals were euthanized and excluded from analysis (approximately 2\%). For some parameters (alveolar inflammatory cells count, alveolar protein content, and collagen deposition), the two lungs were analyzed separately, since the injury was induced only on the right lung. The contralateral (left) lung has been considered like an internal control.

\section{Pulmonary function}

At the time of sacrifice, mice were anesthetized with ketamine $(100 \mathrm{mg} / \mathrm{kg})$ and xylazine $(4 \mathrm{mg} / \mathrm{kg})$, and mechanically ventilated. In order to standardize lung recruitment, a maneuver ( $30 \mathrm{~cm} \mathrm{H_{2 }} \mathrm{O}$ for $10 \mathrm{sec}$ ) was performed immediately after intubation. A pressure-volume (PV) curve was constructed by delivering five steps of inspiratory volume $(200 \mu \mathrm{L})$ from functional residual capacity. For each step, the plateau pressure was recorded in order to calculate the static compliance by using a pressure transducer, which was interfaced to a PowerLab (AD Instruments) signal transduction unit. A mean value was calculated. After mechanical properties were measured, the chest was opened and a blood sample $(0.1 \mathrm{~mL})$ was withdrawn from the left ventricle and analyzed with an I-STAT 1 portable analyzer to analyze oxygenation value $\left(\mathrm{PaO}_{2}\right)$ (Oxford Instruments S.M., Burke e Burke) (16).

\section{Inflammatory response}

An aliquot of each blood sample was used to perform peripheral leukocyte (WBCs) counts. Subsequently, bronchoalveolar lavage (BAL) was performed separately for each lung, by clamping alternatively the left and right bronchus. Lavage was performed three times for each lung, with 600 or $400 \mu \mathrm{L}$ of lavage solution $(0.9 \%$ saline solution and protease inhibitor) respectively for the right and the left one. The BAL samples obtained were then centrifuged for 10 minutes, $1500 \mathrm{rpm}, 4^{\circ} \mathrm{C}$; the supernatant was then stored at $-80^{\circ} \mathrm{C}$ for subsequent analyses. The cell pellet was resuspended in $500 \mu \mathrm{L}$ PBS (Dulbecco's phosphate-buffered saline; GIBCO). Subsequently, a $100 \mu \mathrm{L}$ aliquot was put in $200 \mu \mathrm{L}$ of Turk (acetic acid gentian violet solution; Merck) for total leukocyte 
count in a Burker chamber, while another $100 \mu \mathrm{L}$ aliquot was centrifuged by a Cytospin (Centrifuge, MPW-351R, MPW) and then stained with a Diff-Quick kit (Medion Diagnostics) that differentially marks the nucleus and cytoplasm, thus facilitating a differential cell count (17).

Protein contents in BAL fluid were performed by the BCA (bicinchoninic acid) method at 24 hours and 14 days. Briefly, $200 \mu \mathrm{L}$ of reagent (composed of 1:50 BCA and $\mathrm{CuSO}_{4}$; Merck) was added to the samples. A standard curve was constructed with varied concentrations of bovine serum albumin; spectrophotometric measurement was performed at $570 \mathrm{~nm}$ with a multilabel spectrophotometer Victor ${ }^{3}$ (Perkin Elmer) (18).

\section{Hydroxyproline (OH-Pro) assay}

After exsanguination, a macroscopic observation of the lungs allowed identifying the localization of the acid injury; lungs were then excised and stored at $-80^{\circ} \mathrm{C}$. Collagen content was measured with the $\mathrm{OH}$-Pro assay. We used the conventional method (19), which entails lung tissue homogenization and hydrolysis with $6 \mathrm{~N} \mathrm{HCl}$ at $120^{\circ} \mathrm{C}$, followed by chloramine T and Ehrlich's solution (Merck) addition to samples for the $\mathrm{OH}$-proline oxidation and a colorimetric reaction. Finally, absorbance was measured at $550 \mathrm{~nm}$ with a multilabel spectrophotometer Victor ${ }^{3}$.

\section{Histological analysis}

At sacrifice, some mice were devoted to histological analysis. Briefly, lung tissue was fixed in $4 \%$ paraformaldehyde and embedded in paraffin. Sections were stained with hematoxylin-eosin (H\&E) (automatic stainer Dako CoverStainer) and Masson's trichrome (automatic stainer Dako Artisan Link Pro Special Staining System). Morphological changes were analyzed by two experienced pathologists in a blinded fashion (Light Microscope Leica DM 2500 and Digital Microimaging Device Leica DMD108).

\section{Statistical analysis}

Data are expressed as mean \pm standard error of the mean (SEM). Differences in variances between treatment groups were assessed by one-way analysis of variance (ANOVA) and Tukey post hoc test. $P$ values of less than 0.05 (two-tailed) were considered as statistically significant. In the Acute ARDS study, ANOVA was performed in experimental groups sacrificed at 6 hours and at 24 hours separately. Statistical analysis was performed by GraphPad Prism (version 8.4.2).

\section{Results}

\section{Acute ARDS study}

\section{Pulmonary function}

Acid instillation, as expected, reduced respiratory compliance (Fig. 1A); specifically, at 6 and 24 hours postinstillation respiratory compliance was significantly reduced by $30 \%(p<0.01)$ and $21 \%(p<0.05)$, respectively, compared with healthy mice. Mice presented no apparent adverse

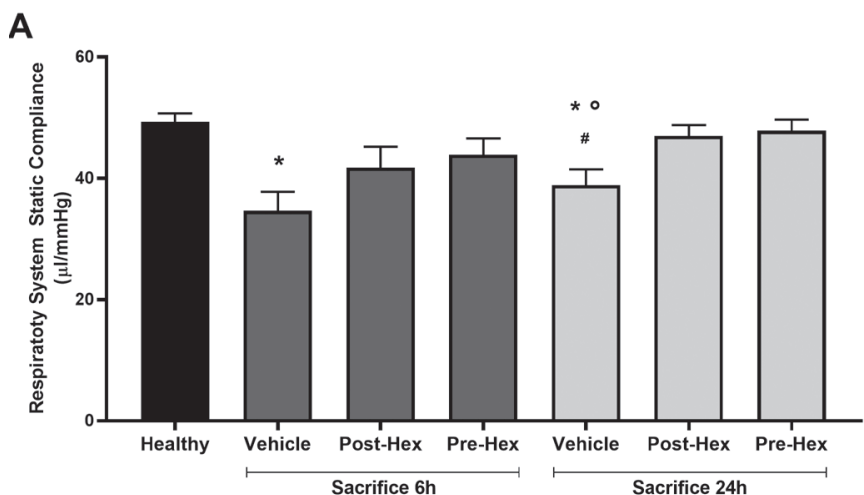

B

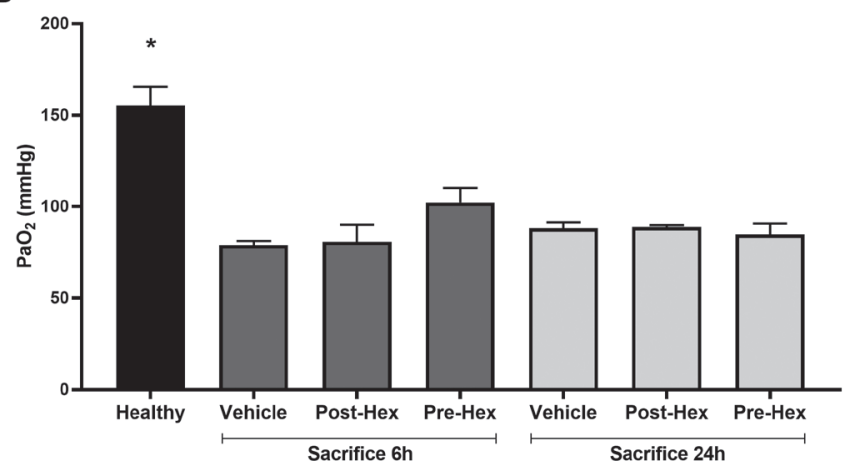

Fig. 1 - Respiratory system static compliance (panel A) and oxygenation (panel B). Respiratory system static compliance derived from the pressure-volume curve construction and oxygenation $\left(\mathrm{PaO}_{2}\right)$ was measured by arterial blood from the left ventricle.

A) Analysis of variance (ANOVA) in sacrifice $6 \mathrm{~h}$ experiment $p<0.05$, Tukey post hoc test; ${ }^{*} p<0.05$ vs. Healthy; ANOVA in Sacrifice $24 \mathrm{~h}$ experiment $p<0.01$, Tukey post hoc test; ${ }^{*} p<0.05$ vs. Healthy, ${ }^{\circ} p<0.05$ vs. Post-Hex, $\# p<0.05$ vs. Pre-Hex.

B) ANOVA in Sacrifice $6 \mathrm{~h}$ experiment $p<0.01$, Tukey post hoc test; ${ }^{*} p<0.01$ vs. Vehicle, Post-Hex and Pre-Hex; ANOVA in Sacrifice $24 \mathrm{~h}$ experiment $p<0.01$, Tukey post hoc test; ${ }^{*} p<0.01$ vs. Vehicle, PostHex, and Pre-Hex.

Healthy: no surgical interventions or treatment $(n=5)$; Vehicle: $\mathrm{HCl}$ instillation + vehicle treatment $(n=8)$; Post-Hex: $\mathrm{HCl}$ instillation + Hexarelin treatment $(n=8)$; Pre-Hex: Hexarelin pretreatment $+\mathrm{HCl}$ instillation $(n=8)$.

responses to hexarelin pretreatment or treatment regimes; moreover, hexarelin administration, in both treatment regimes, modulated acid-reduced respiratory compliance. To illustrate, at 6 hours post-instillation the beneficial effects of hexarelin were slight but not significant; by contrast, hexarelin induced a significant $(\mathrm{p}<0.05)$ improvement in respiratory compliance 24 hours after lung injury. By comparison, arterial oxygen partial pressure $\left(\mathrm{PaO}_{2}\right)$ was severely and significantly decreased in all acid-treated animals $(p<0.01)$ compared with Healthy mice (Fig. 1B).

\section{Inflammatory response}

Total numbers of peripheral white blood cells, an assumed index of systemic inflammation, increased significantly 6 hours after acid instillation (Fig. 2A) in both vehicle$(p<0.01)$ and hexarelin-treated $(p<0.05)$ groups compared 

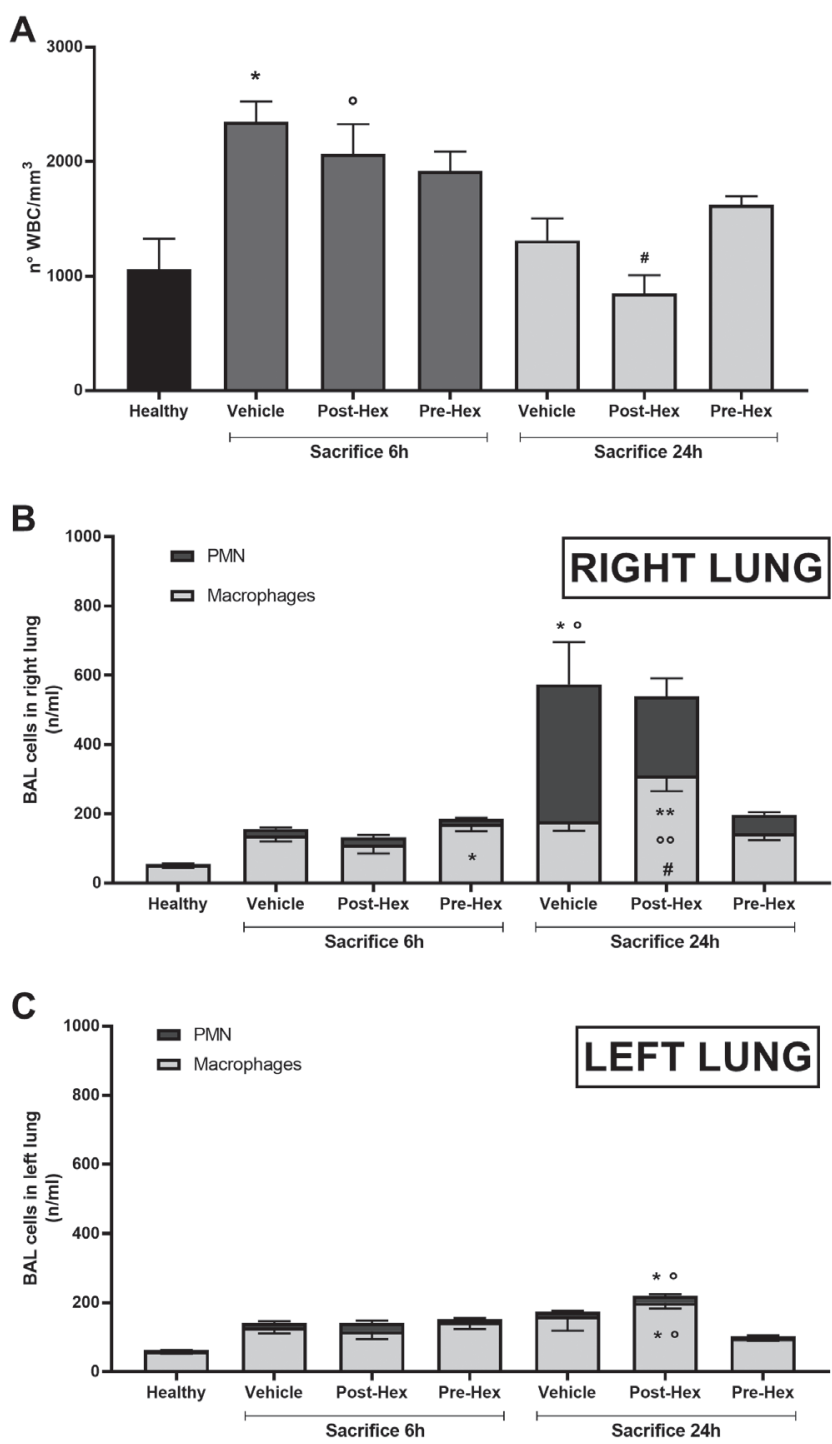

Fig. 2 - Peripheral and local inflammation: total white blood cells (A) and cell count in bronchoalveolar lavage (BAL) in right (panel $B$ ) and left lung (panel $C$ ). White blood cells were collected from the arterial blood and stained with Turk solution. Alveolar cells were collected by performing BAL and stained with Diff-Quik reagent solution.

A) Analysis of variance (ANOVA) in Sacrifice $6 \mathrm{~h}$ experiment $p<0.01$, Tukey post hoc test; ${ }^{*} p<0.01$ vs. Healthy, ${ }^{\circ} p<0.05$ vs. Healthy; ANOVA in Sacrifice $24 \mathrm{~h}$ experiment $\mathrm{p}<0.05$, Tukey post hoc test; $\# p<0.05$ vs. Pre-Hex.

B) Polymorphonuclear (PMN): ANOVA in Sacrifice $6 \mathrm{~h}$ experiment $\mathrm{p}=$ NS; ANOVA in Sacrifice $24 \mathrm{~h}$ experiment $\mathrm{p}<0.01$, Tukey post hoc test; ${ }^{*} p=0.01$ vs. Healthy, ${ }^{\circ} p=0.01$ vs. Pre-Hex. Macrophages: ANOVA in Sacrifice $6 \mathrm{~h}$ experiment $\mathrm{p}=0.02$, Tukey post hoc test; ${ }^{*} p=0.01$ vs. Healthy; ANOVA in Sacrifice $24 \mathrm{~h}$ experiment $p<0.01$, Tukey post hoc test; ${ }^{* *} p<0.01$ vs. Healthy, ${ }^{\circ 0} p<0.05$ vs. Vehicle, $\# p<0.01$ vs. Pre-Hex.

c) PMN: ANOVA in Sacrifice $6 \mathrm{~h}$ experiment $\mathrm{p}=\mathrm{NS}$; ANOVA in Sacrifice 24 h experiment $p=0.01$, Tukey post hoc test; ${ }^{*} p<0.05$ vs. Healthy, ${ }^{\circ} p<0.01$ vs. Pre-Hex. Macrophages: ANOVA in Sacrifice $6 \mathrm{~h}$ experiment $p=N S$; ANOVA in Sacrifice $24 \mathrm{~h}$ experiment $p<0.01$, Tukey post hoc test; ${ }^{*} p=0.01$ vs. Healthy, ${ }^{\circ} p<0.05$ vs. Pre-Hex. Healthy: no surgical interventions or treatment $(n=5)$; Vehicle: $\mathrm{HCl}$ instillation + vehicle treatment $(n=8)$; Post-Hex: $\mathrm{HCl}$ instillation + Hexarelin treatment $(n=8)$; Pre-Hex: Hexarelin pretreatment $+\mathrm{HCl}$ instillation $(n=8)$. with healthy mice. At 24 hours post-instillation, total cell numbers decreased in all groups; in particular, cell numbers returned to normal (healthy) levels in hexarelin-treated mice.

Differential cell counts of BAL fluid were strongly influenced both by acid instillation and by hexarelin (Fig. 2B, C). In the BAL of healthy mice, polymorphonuclear (PMN) cells represented $4 \%$ of total white blood cells, the balance of which (96\%) were macrophages. At 6 hours post-acid instillation, there was an important increase in BAL PMN; notably, PMN in the BAL of the pre-hexarelin-treated group was also elevated and significantly $(p=0.010)$ different from those in healthy mice. Acid instillation increased the differential cell count, which achieved maximum levels at 24 hours post-instillation (Fig. 2B, C). At this time, hexarelin treatment and especially pretreatment modulated PMN numbers to a lesser and greater extent. Curiously, macrophage numbers in hexarelin-treated mice were significantly greater compared with other groups in both the right (acid-instilled) as well as the left (acid-naive) lungs.

Indices of local inflammation included the total protein contents and differential cell counts of BAL. Acid instillation induced a very large protein extravasation into alveoli (Tab. I). Hexarelin treatment and pretreatment modulated acidinduced protein leakage; in fact, the BAL protein contents in both hexarelin-treated groups (6 hours post-instillation) were comparable with those of healthy mice and significantly smaller $(p<0.01)$ than those in the acid-instilled-alone group.

TABLE I - Local inflammation: total protein BAL content in right and left lung by BCA method

\begin{tabular}{llcc}
\hline & Groups & Right lung & Left lung \\
\hline & Healthy & $268 \pm 24$ & $423 \pm 54$ \\
\hline Sacrifice 6 h & Vehicle & $2994 \pm 496^{*, \circ}$ & $1148 \pm 193$ \\
& Post-Hex & $1585 \pm 316$ & $1380 \pm 262$ \\
& Pre-Hex & $1647 \pm 315$ & $1013 \pm 294$ \\
\hline Sacrifice 24 h & Vehicle & $2891 \pm 289^{* *}$ & $773 \pm 103$ \\
& Post-Hex & $2145 \pm 266^{\circ \circ}$ & $616 \pm 70$ \\
& Pre-Hex & $2364 \pm 296^{\#}$ & $521 \pm 90$ \\
\hline
\end{tabular}

In the right lung: ANOVA in Sacrifice $6 \mathrm{~h}$ experiment $\mathrm{p}<0.01$, Tukey post hoc test; ${ }^{*} p<0.01$ vs. Healthy, ${ }^{\circ} p<0.05$ vs. Post-Hex; ANOVA in Sacrifice $24 \mathrm{~h}$ experiment $p<0.01$, Tukey post hoc test; ${ }^{* *} p<0.01$ vs. Healthy, ${ }^{\circ 0} p<0.01$ vs Healthy, ${ }^{*}<<0.01$ vs. Healthy. In the left lung: ANOVA $p=n s$. Healthy: no surgical interventions or treatment $(n=5)$; Vehicle: $\mathrm{HCl}$ instillation + vehicle treatment $(n=8)$; Post-Hex: $\mathrm{HCl}$ instillation + Hexarelin treatment $(n=8)$; Pre-Hex: Hexarelin pretreatment $+\mathrm{HCl}$ instillation $(n=8)$.

ANOVA = analysis of variance; $\mathrm{BAL}=$ bronchoalveolar lavage; $\mathrm{BCA}=$ bicinchoninic acid.

\section{Late ARDS study}

Body weight was monitored throughout the experiment, since it is known that hexarelin stimulates food intake. As expected, mice belonging to acid-instilled groups showed a significant $(p<0.01)$ loss of body weight 48 hours after $\mathrm{HCl}$ administration, compared with healthy mice (Fig. 3A). 


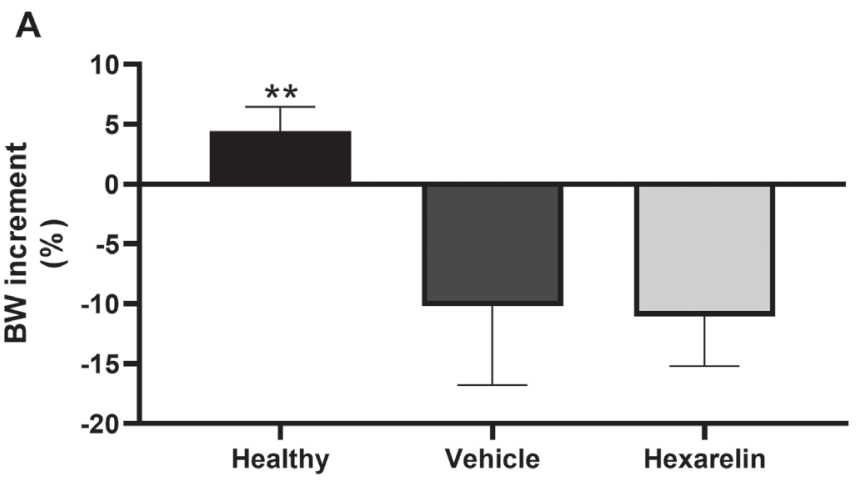

B

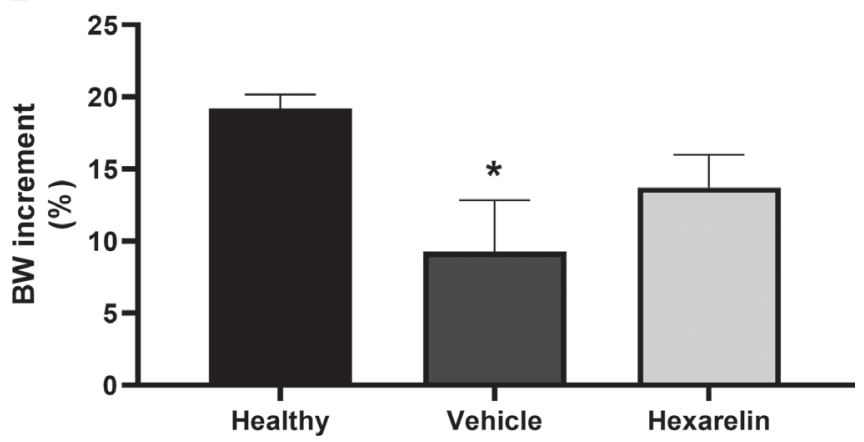

Fig. 3 - Body weight increment in 48 hours (panel A) and in 14 days (panel B).

A) Analysis of variance (ANOVA) $p<0.0001$, Tukey post hoc test; ${ }^{*} p<0.01$ vs. Vehicle and Hexarelin.

B) ANOVA $p=0.048$, Tukey post hoc test; ${ }^{*} p<0.05$ vs. Healthy. Healthy: no surgical interventions or treatment $(n=15)$; Vehicle: $\mathrm{HCl}$ instillation + Vehicle treatment $(n=18)$; Hexarelin: $\mathrm{HCl}$ instillation + Hexarelin treatment $(n=18)$.

Fourteen days post-instillation body weights of mice in the vehicle group were significantly $(p<0.05)$ smaller than those of healthy mice; hexarelin treatment preserved body weight better than vehicle treatment alone (Fig. 3B).

\section{Pulmonary function}

By 14 days post-instillation, respiratory system static compliance did not differ significantly between groups. Acidtreated mice showed no different (ANOVA, $p=n s$ ) mechanical properties $(51.6 \pm 3.0$ and $51.0 \pm 3.4 \mu \mathrm{L} / \mathrm{mm} \mathrm{Hg}$ in Vehicle and Hexarelin groups, respectively) compared with healthy mice $(58.0 \pm 4.5 \mu \mathrm{L} / \mathrm{mm} \mathrm{Hg})$.

\section{Collagen deposition}

In order to estimate fibrosis development at 14 days postinstillation, the collagen content of each lung was measured indirectly with the $\mathrm{OH}$-Pro assay. The collagen contents of both right and left lungs of the hexarelin-treated group were smaller compared with those in the vehicle-treated group; however, only the right lungs showed a statistically significant difference $(p<0.05)$ between the hexarelin- and vehicletreated groups (Fig. 4A).
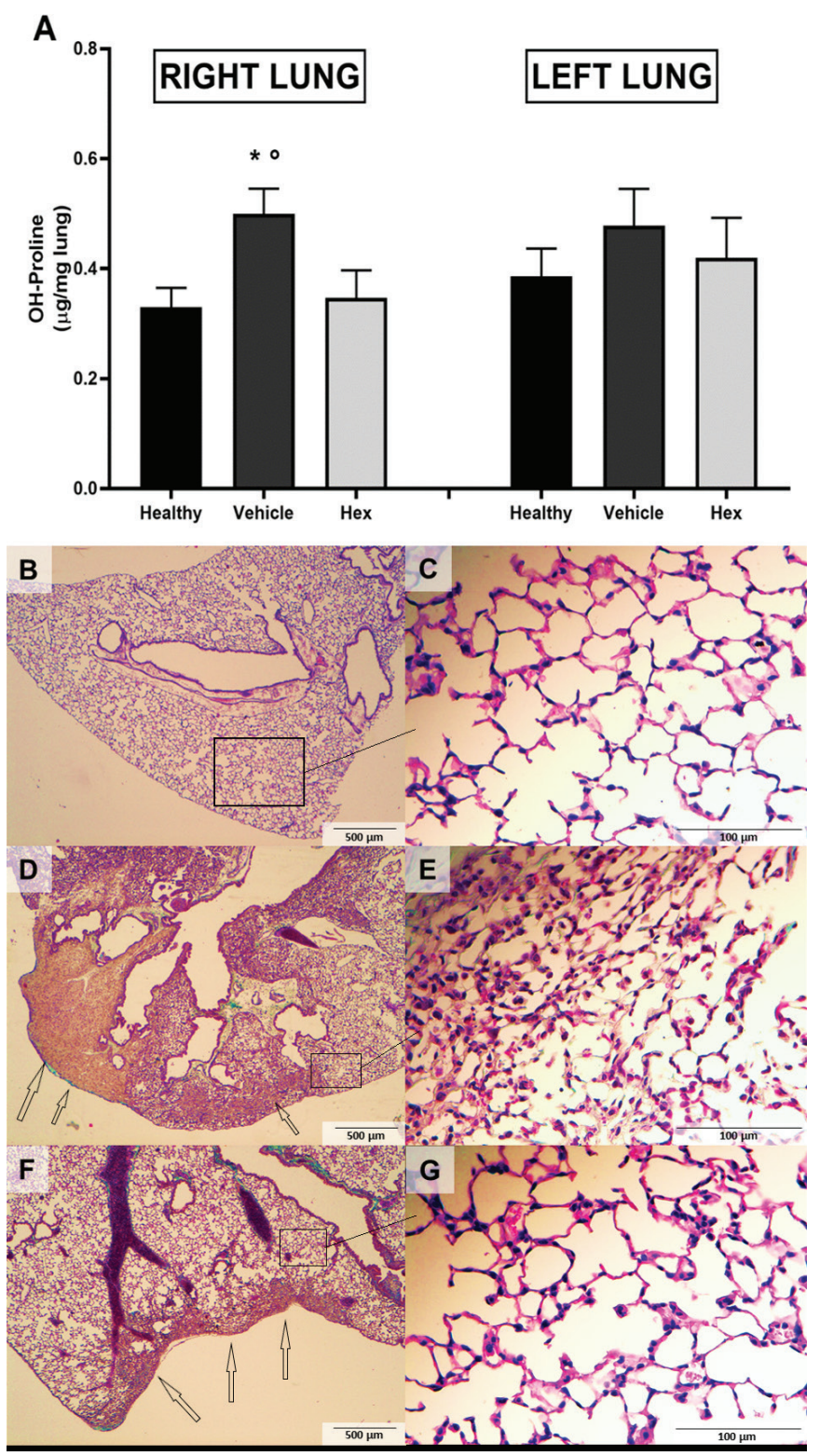

Fig. 4 - Lung fibrosis: OH-Proline lung content $(A)$ and effects of hexarelin on lung histology (B) in acid-injured mice 14 days after lung injury induction.

The collagen deposition was evaluated by the assessment of $\mathrm{OH}$-proline content in lung-homogenized tissue with chloramine T and Ehrlich's solutions.

In right lung: Analysis of variance (ANOVA) $p<0.05$, Tukey post hoc; ${ }^{*} p<0.05$ vs. Hexarelin, ${ }^{\circ} p<0.05$ vs. Healthy. In left lung: ANOVA $p=$ NS. Healthy: no surgical interventions or treatment $(n=10)$; Vehicle: $\mathrm{HCl}$ instillation + vehicle treatment $(n=13) ;$ Hexarelin: $\mathrm{HCl}$ instillation + Hexarelin treatment $(n=13)$.

Histology: Representative images are shown.Tissues were prepared for Masson's trichrome staining. (B, D, F: 40x magnification; C, E, G: 400x magnification.) (B, C) Healthy: no surgical interventions or treatment $(n=4) ;(D, E)$ Vehicle: $\mathrm{HCl}$ instillation + vehicle treatment $(n=3)$; and $(\mathbf{F}, \mathbf{G})$ Hexarelin: $\mathrm{HCl}$ instillation + Hexarelin treatment $(n=5)$. Areas of fibrosis (stained in green) are indicated with arrows; boxes on the $40 \times$ images indicate the locations of the $400 \times$ images. 


\section{Histological examination}

In healthy mice, lung parenchyma was substantially preserved with normal lobular structure, slight bronchial ectasia, normal alveoli, and alveolar ducts (Fig. 4B, C). In the vehicle-treated group, lung tissue was characterized by diffuse areas of fibrosis, especially subpleural with centrilobular extension. This fibrosis was of a "young" type, with several fibroblastic cells in deposits of collagen and with large subpleural nodules; as well, several small "fibroblastic foci" were found in adjacent parenchyma. There was also evidence of architectural distortion with marked bronchiolar dilatation forming cystic spaces resembling honeycombing-like features (Fig. 4D). In a vehicle-treated (acid-instilled) lung there was evidence of a slight alveolar distortion, accompanied by many alveolar macrophages and some PMN cells (Fig. 4E). In hexarelin-treated mice, by contrast, fibrosis was reduced compared to that of the vehicle-treated group; fibrotic distribution was patchy with subpleural localization prevalent. This fibrotic tissue was similar to that previously described; that is, appearing young and cellulated and accompanied by evidence of abrupt transitions from remodeled lung parenchyma to normal alveolar walls. At the center of a lobule, the presence of a fibroblastic focus is obvious (Fig. 4F). Almost normal alveolar walls and only some inflammatory cells were evident in lungs from hexarelin-treated mice (Fig. 4G).

\section{Discussion}

In this study, we demonstrate protective effects of hexarelin against ARDS in a unilateral acid aspiration lung injury model in mice. Our results show that hexarelin treatment significantly (i) ameliorated respiratory system compliance, (ii) reduced protein levels in the BAL, and (iii) blunted PMN infiltration compared with the vehicle-treated group; these effects eventually attenuated lung fibrosis and collagen content. To the best of our knowledge, this is the first study to evaluate the effects of hexarelin on ARDS in a mouse model of unilateral lung acid instillation. Hexarelin, a synthetic hexapeptide, is a powerful agonist of the ghrelin receptor and, consequently, manifests both endocrine and extra-endocrine activities. These activities include positive effects on gastrointestinal-, cardiovascular-, muscular-, and nervous systems, as well as participation in regulation of energy balance (7-11). In humans, hexarelin actions are not restricted to stimulating $\mathrm{GH}$ release; to illustrate, acute hexarelin administration markedly increased left ventricular function in (i) normal subjects, (ii) in patients with ischemic cardiomyopathy, as well as (iii) in patients with severe $\mathrm{GH}$ deficiency (20). Hexarelin significantly reduced indices of cardiac fibrosis in experimental models of myocardial infarction, likely through an underlying anti-inflammatory mechanism (12). The effects of subacute hexarelin treatments in rats (8) strongly suggested that hexarelin could interfere with the renin-angiotensin-aldosterone system (RAAS). We provided evidence in support of that hypothesis by showing that hexarelin and other synthetic GHS inhibited the activity of ACE (13). The somatic form of ACE is a type I membrane-anchored dipeptidyl carboxypeptidase consisting of two extracellular catalytic domains: the $\mathrm{N}$ - and $\mathrm{C}$-domains specifically catalyze conversion of angiotensin I and bradykinin, respectively $(21,22)$. Hexarelin and synthetic GHS selectively bind to and inhibit the activity of the C-domain, without being metabolized themselves (13). Hexarelin inhibition of ACE may account, in part, for its cardioprotective effects. To illustrate, binding sites for GHS are expressed in the heart; moreover, mRNA for the specific GHS receptor (GHS-R1a) has been detected by reverse transcriptase polymerase chain reaction (RT-PCR) in the rat aorta as well as the left ventricle and left atrium $(23,24)$. Nonetheless, it is presumed that the levels of GHS-R1a expressed in these tissues are too small to be responsible for GHS cardioprotective effects. GHS cardioprotective effects are now being considered to be more related to inhibition of angiotensin II (AII) synthesis and/or the antagonism of its receptor (AT1). ACE synthesizes All, which acts through the AT1 receptor to increase blood pressure and to promote fibrosis and inflammation. The vulnerability of All to enzymatic conversion by ACE2 leads to reduction of All levels and production of angiotensin (1-7) which selectively binds to the MAS receptor. The beneficial effects of ACE2 activity may be both systemic as well as localized in tissues, such as the heart, kidneys, and lungs, where it antagonizes pathological changes (25).

Our results that demonstrate hexarelin inhibition of lung fibrosis in acid-instilled mice are in agreement with our previous results demonstrating the cardioprotective and antiinflammatory effects of hexarelin $(8,26)$. Collectively, these findings strongly suggest that hexarelin may inhibit the development of pathological fibrosis in both these organs.

The lack of beneficial effect of hexarelin on oxygenation could depend on the short interval after treatment: it is possible that 24 hours is not enough to affect oxygen exchange. An impaired perfusion could also prevent an increase in oxygenation.

The precise pathogenesis of fibrotic pulmonary disorder is still unclear; it could result from an excessive host inflammatory response of the lung to an infectious or noninfectious insult. A common feature is collagen accumulation that leads to destruction of alveolar structures and promotes remodeling. This purported mechanism has been proposed to play a primary role in ARDS (27). In the lung and other tissues, inflammation correlates with the presence of macrophages and other immune cells that can be involved in the inflammatory process and thereafter its resolution and recovery from ARDS (28). It has been reported that ARDS occurs in some severe acute respiratory syndrome (SARS) patients despite a diminishing viral load, suggesting that the host immune response rather than viral infection itself could be responsible for lung damage (29). We have observed that hexarelin reduced the number of immune cells in the BAL, in particular PMN, suggesting that it could partially inhibit the recruitment of PMN into the alveolar space. This is consistent with the anti-inflammatory and antifibrotic effects reported for hexarelin in the heart (12). In this study, we observed that hexarelin significantly reduced $\mathrm{OH}$-proline levels, a measure of collagen deposition, in the lung treated with acid instillation. This result is 
consistent with the ability of hexarelin to reduce the fibrotic areas in lung histology.

In our histological observations, fibrosis features were similar in Vehicle- and Hexarelin-treated groups, either for cellular type or anatomical location (subpleural origin with following centrilobular involvement, like usual interstitial pneumonia pattern) (30). The smaller amounts of fibrosis in hexarelin-treated mice could be related to a lower collagen deposition, consistent with the reduced presence of inflammatory cells.

This study has some limitations that should be acknowledged. First, we did not confirm the findings in a different model of ARDS. Second, the possible mechanisms of action of hexarelin are only speculative. Third, the levels of inflammatory cytokines were not measured, which could support the results on inflammation obtained for local and peripheral inflammatory cell count. Fourth, as index of lung, edema, septal thickening, and hemorrhage were not assessed in this study.

In conclusion, our results suggest that hexarelin can ameliorate the static compliance of acid-injured lungs in mice, an experimental model of ARDS. Our results also show that hexarelin can reduce lung fibrosis, a complication often reported in patients with classical and COVID-19 ARDS. Collectively, these findings suggest that hexarelin and other synthetic GHS may be successfully co-opted for use in antagonizing lung and cardiac fibrosis.

\section{Acknowledgments}

Conflict of interest: The authors declare that the research was conducted in the absence of any commercial or financial relationships that could be construed as a potential conflict of interest.

Funding/Support: We acknowledge that this research was partially supported by the Italian Ministry of University and Research (MIUR), Department of Excellence project PREMIA (PREcision Medlcine Approach: bringing biomarker research to clinic). Dr. Emanuele Rezoagli was supported by the International Young Investigator Award 2018 from the European Society of Intensive Care Medicine (ESICM) with the project titled: "Role of the exhaled breath condensate as non-invasive monitoring of the lung inflammation during ARDS: a prospective cohort study" and by the National Merck Sharp \& Dohme Corporation Research Award 2017 from the Società Italiana di Anestesia Analgesia Rianimazione e Terapia Intensiva (SIAARTI) with the project titled: "Studio della concentrazione di ossido nitrico nell'esalato espiratorio come marcatore di danno polmonare acuto in pazienti adulti con ARDS sottoposti a ventilazione meccanica."

\section{References}

1. Bellani G, Laffey JG, Pham T, et al; LUNG SAFE Investigators; ESICM Trials Group. Epidemiology, patterns of care, and mortality for patients with acute respiratory distress syndrome in intensive care units in 50 countries. JAMA. 2016;315(8):788800. CrossRef PubMed

2. McNicholas BA, Rooney GM, Laffey JG. Lessons to learn from epidemiologic studies in ARDS. Curr Opin Crit Care. 2018;24(1): 41-48. CrossRef PubMed

3. Heymann DL, Shindo N; WHO Scientific and Technical Advisory Group for Infectious Hazards. COVID-19: what is next for public health? Lancet. 2020;395(10224):542-545. CrossRef PubMed
4. Ranieri VM, Rubenfeld GD, Thompson BT, et al; ARDS Definition Task Force. Acute respiratory distress syndrome: the Berlin Definition. JAMA. 2012;307(23):2526-2533. PubMed

5. Ware LB, Matthay MA. The acute respiratory distress syndrome. N Engl J Med. 2000;342(18):1334-1349. CrossRef PubMed

6. Bachofen $M$, Weibel ER. Structural alterations of lung parenchyma in the adult respiratory distress syndrome. Clin Chest Med. 1982;3(1):35-56. CrossRef PubMed

7. Sibilia $V$, Torsello A, Pagani $F$, et al. Effects of hexarelin against acid-independent and acid-dependent ulcerogens in the rat. Peptides. 2004;25(12):2163-2170. CrossRef PubMed

8. Locatelli V, Rossoni G, Schweiger F, et al. Growth hormoneindependent cardioprotective effects of hexarelin in the rat. Endocrinology. 1999;140(9):4024-4031. CrossRef PubMed

9. Biagini G, Torsello A, Marinelli C, et al. Beneficial effects of desacyl-ghrelin, hexarelin and EP-80317 in models of status epilepticus. Eur J Pharmacol. 2011;670(1):130-136. CrossRef PubMed

10. Conte E, Camerino GM, Mele A, et al. Growth hormone secretagogues prevent dysregulation of skeletal muscle calcium homeostasis in a rat model of cisplatin-induced cachexia. J Cachexia Sarcopenia Muscle. 2017;8(3):386-404. CrossRef PubMed

11. Bresciani E, Pitsikas N, Tamiazzo L, et al. Feeding behavior during long-term hexarelin administration in young and old rats. J Endocrinol Invest. 2008;31(7):647-652. CrossRef PubMed

12. Mao Y, Tokudome T, Kishimoto I. The cardiovascular action of hexarelin. J Geriatr Cardiol. 2014;11(3):253-258. PubMed

13. Torsello A, Bresciani E, Ravelli M, et al. Novel domain-selective ACE-inhibiting activity of synthetic growth hormone secretagogues. Pharmacol Res. 2012;66(4):317-324. CrossRef PubMed

14. Deng W, Deng Y, Deng J, et al. Losartan attenuated lipopolysaccharide-induced lung injury by suppression of lectin-like oxidized low-density lipoprotein receptor-1. Int J Clin Exp Pathol. 2015;8(12):15670-6. PubMed

15. Torsello A, Bresciani E, Rossoni G, et al. Ghrelin plays a minor role in the physiological control of cardiac function in the rat. Endocrinology. 2003;144(5):1787-1792. CrossRef PubMed

16. Amigoni $M$, Bellani $G$, Scanziani $M$, et al. Lung injury and recovery in a murine model of unilateral acid aspiration: functional, biochemical, and morphologic characterization. Anesthesiology. 2008;108(6):1037-1046. CrossRef PubMed

17. Amigoni M, Bellani $G$, Zambelli V, et al. Unilateral acid aspiration augments the effects of ventilator lung injury in the contralateral lung. Anesthesiology. 2013;119(3):642-651. CrossRef PubMed

18. Zambelli V, Bellani G, Borsa R, et al. Angiotensin-(1-7) improves oxygenation, while reducing cellular infiltrate and fibrosis in experimental Acute Respiratory Distress Syndrome. Intensive Care Med Exp. 2015;3(1):44. CrossRef PubMed

19. Tager AM, Kradin RL, LaCamera P, et al. Inhibition of pulmonary fibrosis by the chemokine IP-10/CXCL10. Am J Respir Cell Mol Biol. 2004;31(4):395-404. CrossRef PubMed

20. Broglio F, Benso A, Valetto MR, et al. Growth hormone-independent cardiotropic activities of growth hormone-releasing peptides in normal subjects, in patients with growth hormone deficiency, and in patients with idiopathic or ischemic dilated cardiomyopathy. Endocrine. 2001;14(1):105-108. CrossRef PubMed

21. Soubrier F, Alhenc-Gelas F, Hubert C, et al. Two putative active centers in human angiotensin l-converting enzyme revealed by molecular cloning. Proc Natl Acad Sci USA. 1988;85(24):93869390. CrossRef PubMed

22. Georgiadis D, Beau F, Czarny B, Cotton J, Yiotakis A, Dive V. Roles of the two active sites of somatic angiotensin-converting 
enzyme in the cleavage of angiotensin I and bradykinin: insights from selective inhibitors. Circ Res. 2003;93(2):148154. CrossRef PubMed

23. Katugampola SD, Pallikaros Z, Davenport AP. [125I-His(9)]ghrelin, a novel radioligand for localizing GHS orphan receptors in human and rat tissue: up-regulation of receptors with athersclerosis. Br J Pharmacol. 2001;134(1):143-149. CrossRef PubMed

24. Nagaya N, Miyatake K, Uematsu M, et al. Hemodynamic, renal, and hormonal effects of ghrelin infusion in patients with chronic heart failure. J Clin Endocrinol Metab. 2001;86(12):5854-5859. CrossRef PubMed

25. Kuba K, Imai Y, Ohto-Nakanishi T, Penninger JM. Trilogy of ACE2: a peptidase in the renin-angiotensin system, a SARS receptor, and a partner for amino acid transporters. Pharmacol Ther. 2010; 128(1):119-128. CrossRef PubMed

26. Bulgarelli I, Tamiazzo L, Bresciani E, et al. Desacyl-ghrelin and synthetic $\mathrm{GH}$-secretagogues modulate the production of inflammatory cytokines in mouse microglia cells stimulated by beta-amyloid fibrils. J Neurosci Res. 2009;87(12):2718-2727. CrossRef PubMed

27. Fukuda Y, Ishizaki M, Masuda Y, Kimura G, Kawanami O, Masugi $Y$. The role of intraalveolar fibrosis in the process of pulmonary structural remodeling in patients with diffuse alveolar damage. Am J Pathol. 1987;126(1):171-182. PubMed

28. Aggarwal NR, King LS, D’Alessio FR. Diverse macrophage populations mediate acute lung inflammation and resolution. Am J Physiol Lung Cell Mol Physiol. 2014;306(8):L709-L725. CrossRef PubMed

29. Peiris JS, Yuen KY, Osterhaus AD, Stöhr K. The severe acute respiratory syndrome. N Engl J Med. 2003;349(25):2431-2441. CrossRef PubMed

30. Blackwell TS, Tager AM, Borok Z, et al. Future directions in idiopathic pulmonary fibrosis research. An NHLBI workshop report. Am J Respir Crit Care Med. 2014;189(2):214-222. CrossRef PubMed 